\title{
Assessment of the severity of liver disease and fibrotic change: The usefulness of hepatic CT perfusion imaging
}

\author{
KAZUHIKO HASHIMOTO ${ }^{1}$, TAKAMICHI MURAKAMI ${ }^{2}$, KEIZO DONO ${ }^{1}$, MASATOSHI HORI ${ }^{2}$, TONSOK KIM ${ }^{2}$, \\ MASAYUKI KUDO $^{3}$, SHIGERU MARUBASHI ${ }^{1}$, ATSUSHI MIYAMOTO ${ }^{1}$, YUTAKA TAKEDA ${ }^{1}$, \\ HIROAKI NAGANO $^{1}$, KOJI UMESHITA ${ }^{1}$, HIRONOBU NAKAMURA ${ }^{2}$ and MORITO MONDEN ${ }^{1}$ \\ Departments of ${ }^{1}$ Surgery, and ${ }^{2}$ Radiology, Graduate School of Medicine, Osaka University, Osaka; \\ ${ }^{3}$ Imaging Application Tech Center GE Healthcare, Tokyo, Japan
}

Received December 22, 2005; Accepted March 30, 2006

\begin{abstract}
This study assessed the utility of CT perfusion for quantitative assessment of liver function and fibrosis. Tissue blood flow (TBF), tissue blood volume (TBV), mean transit time (MTT) and hepatic arterial fraction (HAF) were measured with CT perfusion using the deconvolution algorithm in 38 patients with chronic liver diseases and 10 patients without liver disease. Using Child-Pugh classification, 21 patients were classified as Child A, 10 as Child B, and 7 as Child C. In 20 patients, the degree of fibrosis was quantitated in surgicallyresected specimens and compared with the perfusion parameters. The mean TBF, TBV, MTT and HAF of patients without liver disease were $103.9 \pm 18 \mathrm{ml} / \mathrm{min} / 100 \mathrm{~g}, 12.5 \pm 2.0 \mathrm{ml} /$ $100 \mathrm{~g}, 11.1 \pm 1.6 \mathrm{sec}$ and $18.4 \pm 5.6 \%$, respectively $( \pm \mathrm{SD})$. The mean TBF of patients with Child A, B and C were 95.1 \pm 24 , $86.7 \pm 29$ and $75.5 \pm 6.5 \mathrm{ml} / \mathrm{min} / 100 \mathrm{~g}$, respectively. TBF tended to decrease with the severity of chronic liver disease. The mean HAF of patients with Child A, B and C were 18.6 \pm 8.3 , $29.8 \pm 11.2$ and $40.2 \pm 11.1 \%$, respectively. HAF of patients without liver disease was significantly different from those of Child B and C ( $<<0.05$, each). However, there were no significant differences in TBV and MTT between each groups. HAF correlated significantly with the degree of fibrosis $\left(\mathrm{R}^{2}=0.588, \mathrm{p}<0.05\right)$. Our results showed that parameters of CT perfusion correlated significantly with the severity of liver fibrosis and cirrhosis. Quantitative measurement of hepatic tissue blood flow by CT perfusion is useful for evaluation of the severity of disease and fibrotic change.
\end{abstract}

Correspondence to: Dr Keizo Dono, Department of Surgery, Graduate School of Medicine, Osaka University, 2-2 Yamadaoka, Suita, Osaka 565-0871, Japan

E-mail:kdono@surg2.med.osaka-u.ac.jp

Key words: hepatic tissue blood flow, CT perfusion, tissue blood volume, tissue blood flow, mean transit time, hepatic arterial fraction, liver fibrosis

\section{Introduction}

In chronic liver disease, the portal fraction of liver perfusion decreases due to the increase in intrahepatic vascular resistance $(1,2)$. The reduced portal perfusion is partially compensated by an increase in arterial inflow $(1,3,4)$. These quantitative and qualitative hemodynamic changes in cirrhosis have a profound effect on hepatic function and on the clearance of endoand xenobiotics (5-7).

To date, several groups have examined liver function using various imaging methods, such as Doppler ultrasound (8-12), isotope scintigraphy (13-15) and dynamic computed tomography (CT) $(2,16)$. These techniques have not been accepted as the standard methods because of low spatial resolution or poor reproducibility. In the present study, we quantified liver perfusion parameters non-invasively by $\mathrm{CT}$ perfusion based on deconvolution algorithm (17).

Hepatic fibrosis is one of the most important features of chronic hepatitis. Accurate assessment of hepatic fibrosis is important for studying the natural history and prognosis of patients with chronic hepatitis. Several methods are available for assessing hepatic fibrosis and the progression of fibrogenesis in clinical practice and chemical methods are often used to measure the concentration of collagen in liver tissue (18-20). While these are good methods, they require a large sample of liver tissue. Conventional routine histological examination is the most common method, although it is subjective and not quantitative. Moreover, needle biopsy of the liver is invasive and can cause severe complications and liver dysfunction, though the incidence is very low. Therefore, a noninvasive method for assessing the degree of liver fibrosis is desirable.

The purpose of the present study was to compare the changes in perfusion parameters measured with $\mathrm{CT}$ perfusion in patients with and without chronic liver disease, and to assess the utility and clinical usefulness of CT perfusion for quantitative assessment of the severity of disease and fibrotic change.

\section{Materials and methods}

Between April 2003 and April 2004, 38 patients with chronic liver diseases (7 women, 31 men; age range, 32-79 years; mean, $59.1 \pm 11$ years, \pm SD) and 10 patients without liver disease 
Table I. The characteristics of patients who underwent operation.

\begin{tabular}{|c|c|c|c|c|c|c|c|}
\hline No. & Gender & Age & Disease & C-P classification & Operation & $\mathrm{HAF}(\%)$ & Fibrosis rate $(\%)$ \\
\hline 1 & M & 75 & $\mathrm{HCC}$ & $\mathrm{B}$ & Hepatectomy & 18.8 & 12.5 \\
\hline 2 & $\mathrm{~F}$ & 79 & $\mathrm{HCC}$ & A & Hepatectomy & 23.3 & 18.5 \\
\hline 3 & M & 75 & $\mathrm{HCC}$ & A & Hepatectomy & 24.9 & 14.4 \\
\hline 4 & $\mathrm{~F}$ & 63 & $\mathrm{HCC}$ & $\mathrm{C}$ & LDLT & 31.6 & 21.6 \\
\hline 5 & $\mathrm{~F}$ & 48 & Liver cirrhosis & $\mathrm{C}$ & LDLT & 60.4 & 24.6 \\
\hline 6 & M & 71 & ICC & $\mathrm{B}$ & Hepatectomy & 19.3 & 14.3 \\
\hline 7 & M & 68 & ICC & $\mathrm{A}$ & Hepatectomy & 14.9 & 8.8 \\
\hline 8 & M & 32 & $\mathrm{HCC}$ & A & Hepatectomy & 14.5 & 3.4 \\
\hline 9 & M & 54 & $\mathrm{HCC}$ & A & Hepatectomy & 6.6 & 7.9 \\
\hline 10 & M & 55 & $\mathrm{HCC}$ & A & Hepatectomy & 17.4 & 13.7 \\
\hline 11 & M & 51 & $\mathrm{HCC}$ & A & Hepatectomy & 14.8 & 13.6 \\
\hline 12 & $\mathrm{~F}$ & 68 & $\mathrm{HCC}$ & A & Hepatectomy & 14.4 & 8.3 \\
\hline 13 & M & 71 & $\mathrm{HCC}$ & A & Hepatectomy & 14.1 & 6.9 \\
\hline 14 & M & 66 & ICC & A & Hepatectomy & 21.2 & 4.4 \\
\hline 15 & M & 54 & $\mathrm{HCC}$ & A & Hepatectomy & 19.1 & 7.3 \\
\hline 16 & M & 52 & $\mathrm{HCC}$ & B & Hepatectomy & 13.2 & 7.1 \\
\hline 17 & M & 66 & $\mathrm{HCC}$ & A & Hepatectomy & 18.7 & 8.1 \\
\hline 18 & $\mathrm{~F}$ & 58 & $\mathrm{HCC}$ & B & Hepatectomy & 24.3 & 11.8 \\
\hline 19 & M & 53 & $\mathrm{HCC}$ & A & Hepatectomy & 18.2 & 6.9 \\
\hline 20 & M & 36 & Liver cirrhosis & $\mathrm{C}$ & LDLT & 35.3 & 16.8 \\
\hline
\end{tabular}

HCC, hepatocellular carcinoma; ICC, intrahepatic cholangiocarcinoma; C-P classification, Child-Pugh classification; LDLT, living donor liver transplantation.

(5 women, 5 men; age range, 23-50 years; mean age, 35.6 \pm 9 years) underwent CT perfusion examination in our hospital. According to the Child-Pugh classification, 21 patients were classified as Child A, 10 as Child B, and 7 as Child C. Twentythree of the 38 patients with chronic liver disease had hepatocellular carcinoma. The 10 patients without liver disease were donor candidates of living donor liver transplantation, and the diagnosis of normal liver was confirmed by medical history, physical examination, laboratory screening, Doppler sonography of the liver and needle biopsy specimens. Of the 38 patients, 20 had undergone operation (hepatectomy; $n=17$, living donor liver transplantation; $\mathrm{n}=3$, Table I). In the 20 patients, the degree of fibrosis was quantitated in surgicallyresected specimens and compared with the perfusion parameters. All patients provided informed consent to undergo the enhanced CT and CT perfusion examinations and to be included in the study. The study was conducted in accordance with the principles of the Declaration of Helsinki. Ethics Committee in our institute did not require pre-approval of the study.

CT perfusion. CT perfusion study was performed with an 8 channel multidetector-row scanner (LightSpeed Ultra, GE Healthcare, Milwaukee, WI). At first, whole liver images were obtained with a tube voltage of $120 \mathrm{kV}$, a tube current of $300 \mathrm{~mA}$, a rotation period of $0.5 \mathrm{sec}$, a detector collimation of $2.5 \mathrm{~mm}$, and a table increment of $27 \mathrm{~mm} /$ rotation. Images with an effective section thickness of $5 \mathrm{~mm}$ were reconstructed every $5 \mathrm{~mm}$ to provide contiguous sections. Then, CT perfusion study was performed with cine mode scan (1 sec per rotation) at the liver hilar level, determined by whole liver images. The scan parameters employed for CT perfusion study were $120 \mathrm{kV}, 60 \mathrm{~mA}, 1 \mathrm{sec} /$ rotation, $10 \mathrm{~mm}$ slice thickness $\mathrm{x} 2$, cine scan mode, standard reconstruction algorithm, and $35 \mathrm{~cm}$ display field of view (DFOV). A nonionic contrast medium (Iohexol, Omunipaque, Daiichi Pharmaceutical Co., Tokyo, Japan) was injected at $0.5 \mathrm{ml} / \mathrm{kg}$ of $300 \mathrm{mgI} / \mathrm{ml}$ (total dose $25-40 \mathrm{ml}$ ) at a rate of $5 \mathrm{ml} / \mathrm{sec}$ through a 20 gauge plastic cannula inserted into the antecubital vein. This was followed by injection of $30 \mathrm{ml}$ of saline chaser at a rate of $5 \mathrm{ml} / \mathrm{sec}$ with a power injector equipped with double syringe drives. Data acquisition started $8 \mathrm{sec}$ after an initiation of injection of contrast medium and the scan duration was $40 \mathrm{sec}$. Oxygen inhalation at $2 \mathrm{l} / \mathrm{min}$ was provided to facilitate long breathholding during scanning. Image reconstruction was performed every $0.5 \mathrm{sec}$, and these images were transferred to an image processing workstation (Advantage Workstation 4.1, GE Healthcare), to calculate color map images of each blood flow parameter of the liver by using a commercially available software (CT Perfusion 3, GE Healthcare). The blood flow parameters included tissue blood flow (TBF, $\mathrm{ml} / \mathrm{min} / 100 \mathrm{~g}$ ), tissue blood volume (TBV, ml/100 g), mean transit time (MTT, sec) and hepatic arterial fraction (HAF, \%) (Fig. 1).

To calculate each functional map image, regions of interest (ROIs, pixel size; 8-20 pixels) were set on the aorta 

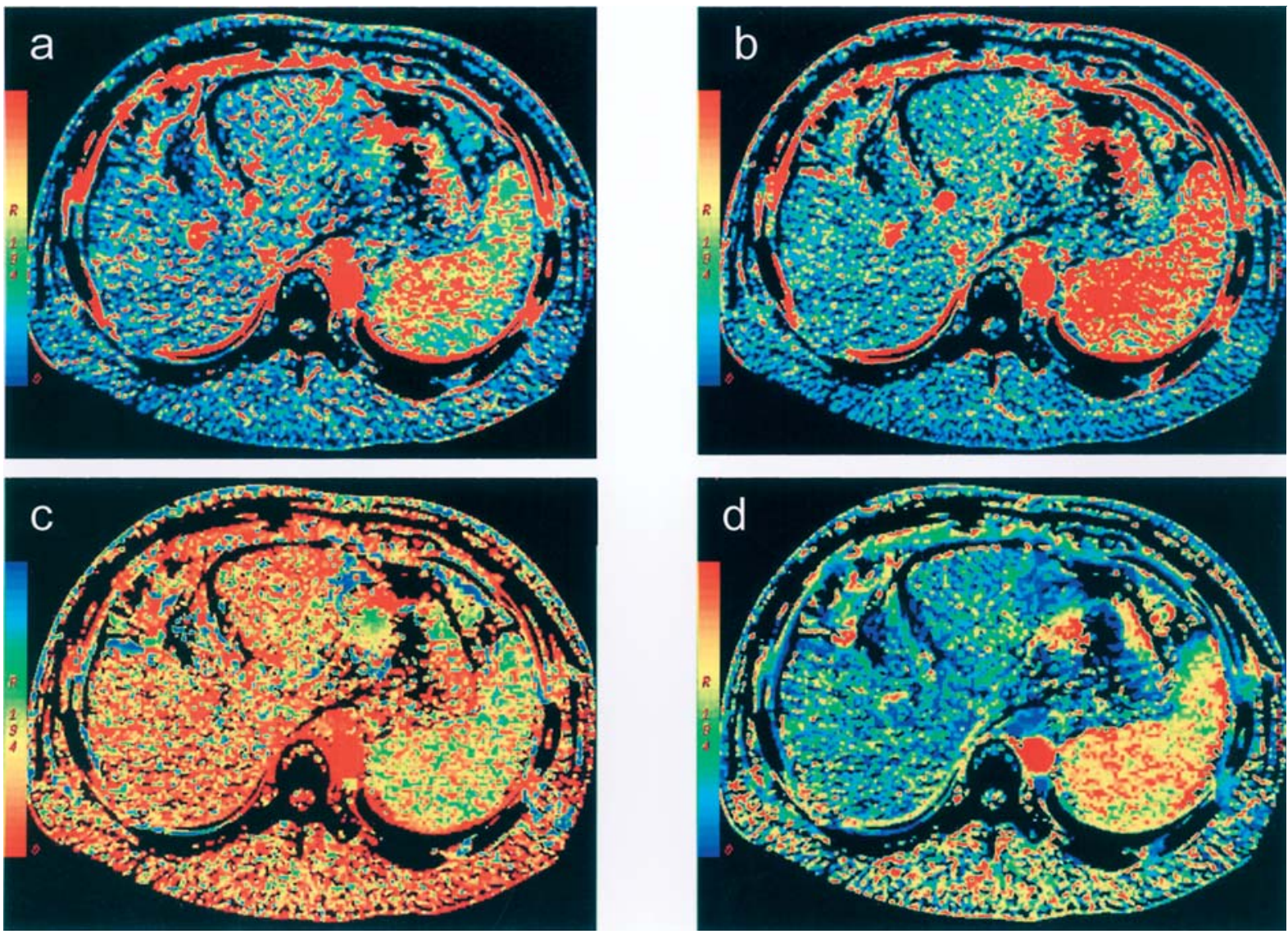

Figure 1. The blood flow parameter maps: a 36-year-old male with liver cirrhosis (hepatitis B virus-related). (a), Hepatic tissue blood flow (TBF), $77.4 \mathrm{ml} /$ $\mathrm{min} / 100 \mathrm{~g}$; (b), Hepatic blood volume (TBV), $9.2 \mathrm{ml} / \mathrm{min}$; (c), Mean transit time (MTT), $12.2 \mathrm{sec}$; (d), Hepatic arterial fraction (HAF), 35.3\%. The degree of fibrosis was quantitated in surgically-resected specimens (Fig. 3) and compared with the perfusion parameters.
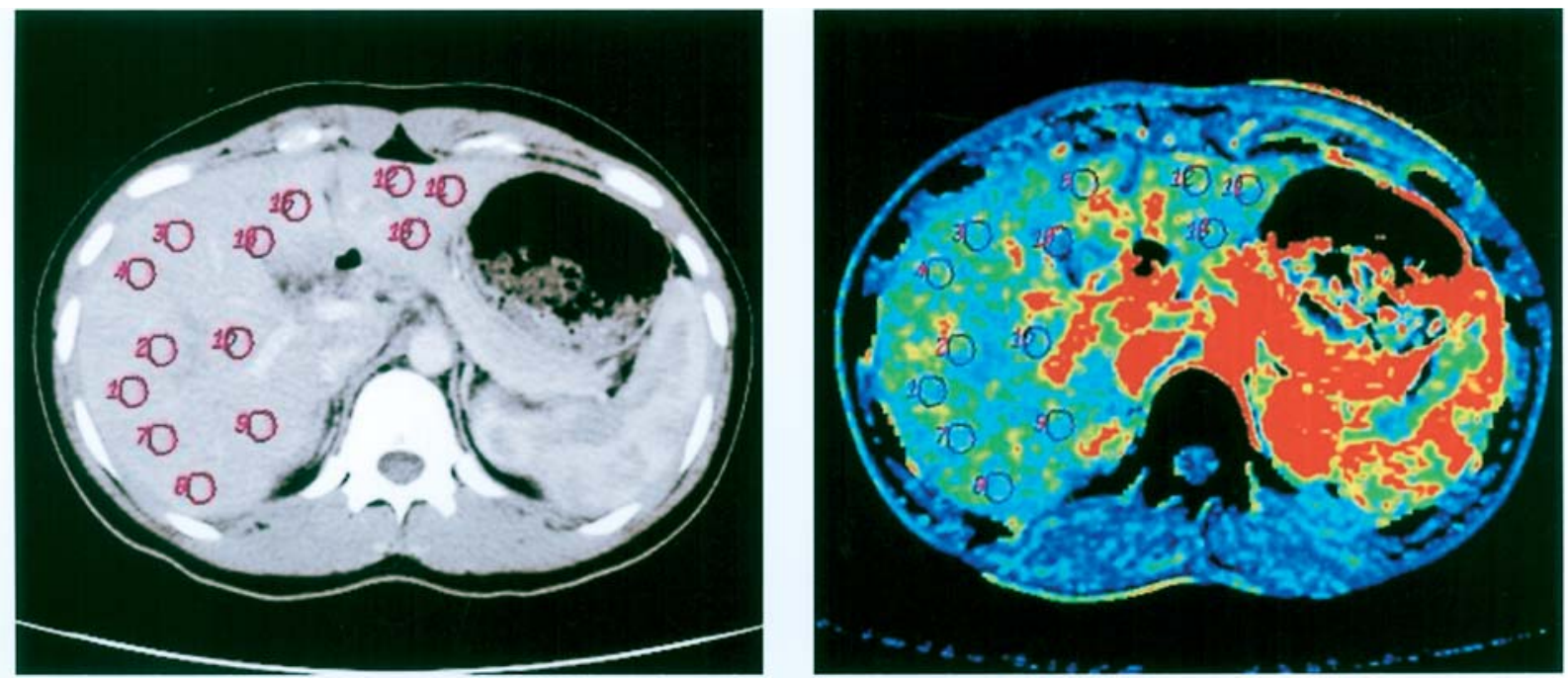

Figure 2. Left, portal venous phase CT image. Right, color map image. 10-20 ROIs (pixel size; 400 pixels) were placed in each section of the liver avoiding intra-hepatic large vessels or tumors confirmed on a CT image.

and the portal vein trunk as input function. At the time of measuring the parameters, one radiologist with 15 years of experience in gastrointestinal and hepatobiliary imaging carefully placed 10-20 ROIs (pixel size; about 400 pixels) on each section of the liver avoiding intra-hepatic large vessels or tumors confirmed on a CT image (Fig. 2). The value of all ROIs were measured and averaged for each case. In our study, the ROIs on the liver parenchyma in patients with hepato- 

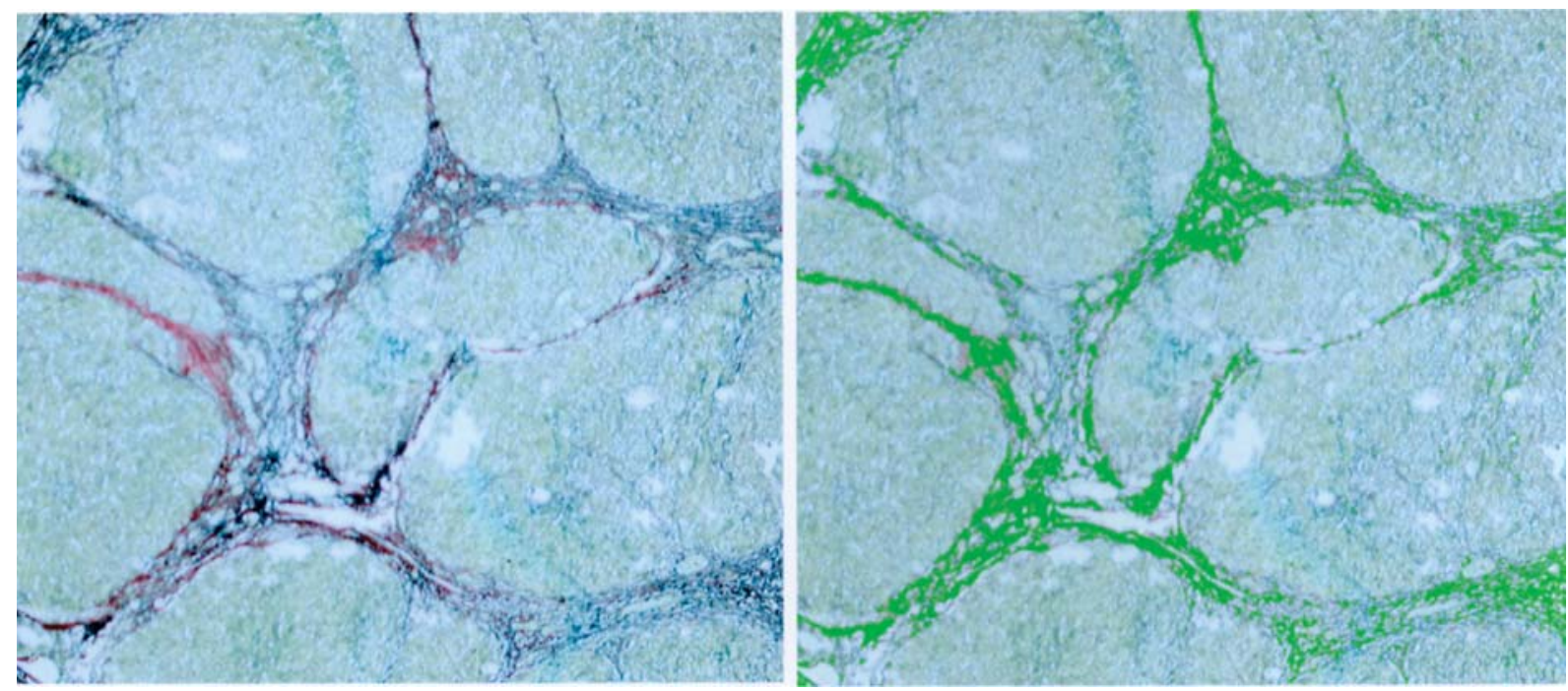

Figure 3. Quantification of hepatic fibrosis. Left, The fibrotic area in the liver specimens was stained by Sirius red, and non-fibrotic area by Fast green (magnification x40). Right, Computer-assisted image analyzed with Mac Scope software. The red area, which was considered the fibrotic area, was assessed by computer-assisted image analysis. In this case, the fibrotic area is $16.8 \%$ of the total area.

cellular carcinoma were drawn in non-tumor segments in order to avoid areas with direct mechanical compression of the portal radicles and the influence of arteriovenous shunt.

Collagen quantification. The degree of hepatic fibrosis was assessed using surgical specimens obtained from 20 patients who had undergone surgery (Table I). Evaluation of the collagen content was done using Sirius red/Fast green staining as previously described $(21,22)$.

The stained sections were quantitated for the extent of fibrosis (percentage of fibrotic area relative to the total area of each microscopic field examined at magnification of $\mathrm{x} 40$ ) by using a modified computerized technique that allowed quantification of the collagen density (Adobe Photoshop 5.0J; Adobe Systems Inc., San Jose, CA). Briefly, the red area, representing the fibrotic area, was measured by an image analysis software (Mac Scope, Mitani Corp., Fukui, Japan) at magnification of $x 40$ (Fig. 3). The mean fibrotic area at five points of the specimen was used for statistical analysis. Quantification of fibrosis was performed by an investigator blinded to the results of the blood flow parameters.

Statistical analysis. Statistical analysis was performed using StatView version 5.0 software (Abacus Concepts Inc., Berkeley, CA). Data for different grades of Child-Pugh classification were compared by the Tukey-Kramer analysis. In the 20 patients who were treated surgically, linear regression analysis was used to determine the correlation between HAF and degree of fibrosis. Data are expressed as mean \pm standard deviation (SD). Statistical significance was defined as a p-value of $<0.05$.

\section{Results}

Perfusion studies are safe and not associated with serious side effects. Each perfusion parameter was successfully calculated in all examined patients. The mean values of TBF,
TBV, MTT and HAF of patients free of liver disease were $103.9 \pm 18 \mathrm{ml} / \mathrm{min} / 100 \mathrm{~g}, 12.5 \pm 2.0 \mathrm{ml} / 100 \mathrm{~g}, 11.1 \pm 1.6 \mathrm{sec}$ and $18.4 \pm 5.6 \%$, respectively (Fig. 4). The TBF values of the liver parenchyma of patients with Child A, Child B and Child C were $95.1 \pm 24,86.7 \pm 29$ and $75.5 \pm 6.5 \mathrm{ml} / \mathrm{min} / 100 \mathrm{~g}$, respectively. The TBF tended to decrease with increased severity of chronic liver disease. TBV values of the liver parenchyma of patients with Child A, Child B and Child C were 11.7 \pm 3.2 , $11.2 \pm 4.5$ and $11.0 \pm 3.2 \mathrm{ml} / 100 \mathrm{~g}$, respectively. The MTT values of the liver parenchyma of patients with Child A, Child B and Child C were 11.2 $\pm 3.1,11.7 \pm 1.7$ and $12.2 \pm 1.3 \mathrm{sec}$, respectively. The HAF values of the liver parenchyma of patients with Child A, Child B and Child C were 18.6 \pm 8.3 , $29.8 \pm 11.2$ and $40.2 \pm 11.1 \%$, respectively. There was no significant difference in TBV and MTT between the groups. HAF of the liver parenchyma significantly increased with increased severity of chronic liver disease (Fig. 4). Significant differences in the HAF of the liver parenchyma were noted between patients with Child A and those with Child B and C $(p<0.05)$, and between patients without liver disease and those with Child B and $\mathrm{C}(\mathrm{p}<0.05)$.

The histopathologically-determined proportions of fibrosis for each of the 20 patients are listed in Table I. The HAF correlated significantly with the proportion of fibrosis in the 20 cases $\left(y=3.303+0.388 x, R^{2}=0.588, p<0.05\right.$, Fig. 5).

\section{Discussion}

Non-invasive measurement of perfusion of parenchymal organs has long been a domain of scintigraphy $(13,23-25)$. However, the major drawback of scintigraphic methods is their limited spatial resolution. It is also difficult to separate overlapping components of arterial and portal venous inflow of radiotracer represented in time-activity curves (26-29), though the liver receives a dual blood supply from the hepatic artery and the portal vein, thus resulting in a bi-phasic inflow of any radiotracer or contrast media. With regard to positron emission 

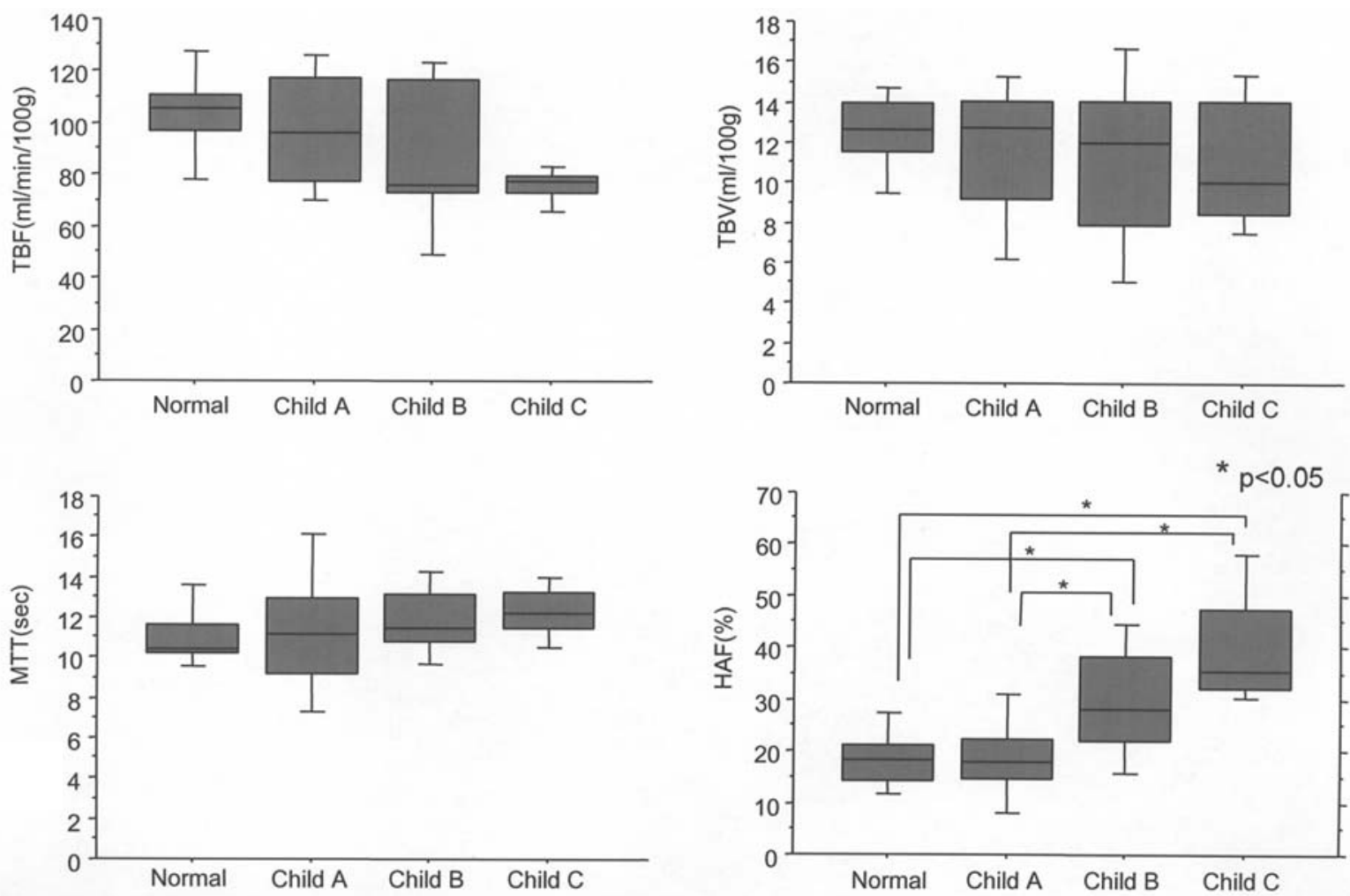

Figure 4. Perfusion parameters according to severity of chronic liver disease. Top left, hepatic tissue blood flow (TBF, $\mathrm{ml} / \mathrm{min} / 100 \mathrm{~g}$ ). Top right, hepatic blood flow (TBV, ml/min). Bottom left, mean transit time (MTT, sec). Bottom right, hepatic arterial fraction (HAF, \%). TBF of the liver parenchyma of patients with Child $\mathrm{C}$ was significantly lower than that without liver disease $(\mathrm{p}<0.05)$. HAF of the liver parenchyma increased significantly with the severity of chronic liver disease. A significant difference in the HAF of the liver parenchyma was seen between patients without liver disease and Child A and those with Child B and C $(\mathrm{p}<0.05)$, and between patients without liver disease and those with Child B and C $(\mathrm{p}<0.05)$.

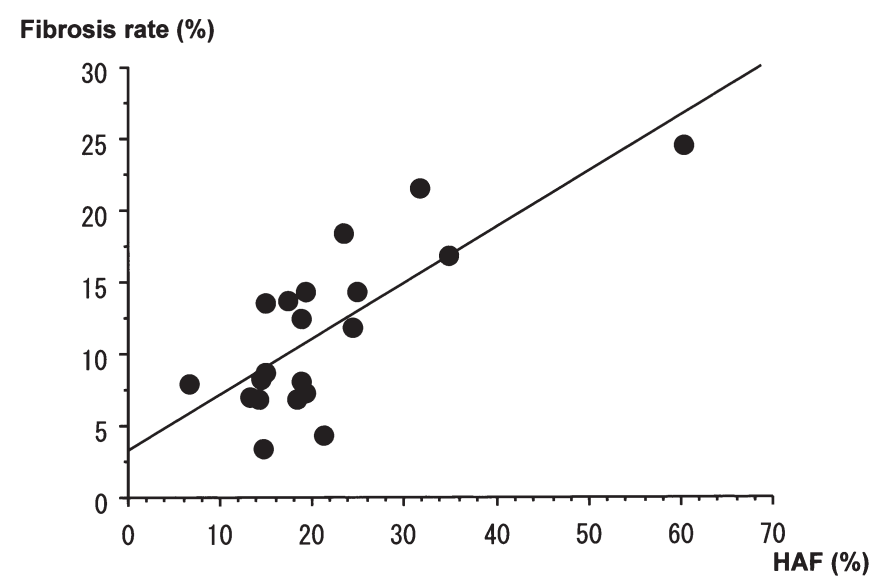

Figure 5. Relationship between HAF and the proportion of liver fibrosis $(n=20)$. Note the significant linear relationship between HAF and proportion of fibrosis $\left(\mathrm{R}^{2}=0.588, \mathrm{p}<0.05\right)$.

tomography (15), which has the best spatial resolution of the nuclear medicine techniques, its use and clinical application are limited due to the high cost.

Doppler and color Doppler US are methods frequently used to evaluate the arterial and portal venous blood supplies of the liver after transplantation and to detect eventual vascular complications $(30,31)$. However, the reproducibility of portal venous flow measurements with Doppler US remains controversial, and arterial flow measurements are even more difficult to obtain with this method because of the small diameter of the hepatic artery $(32,33)$. Doppler US cannot directly measure blood flow in the hepatic parenchyma itself, although it can directly measure the blood flow velocity in only large feeding vessels. Moreover, calculation of the volume flow in these vessels results in inaccuracies because of the inevitable difficulties in measuring the required cross-sectional areas of these vessels (34). Because of these inaccuracies, quantification and evaluation of parenchymal perfusion in the liver is not justified (35).

The application of magnetic resonance imaging (MRI), is associated with difficulties in the quantification of TBF, because signal enhancement of vessels and tissue by nonspecific MR contrast medium, such as gadolinium complex, does not show a linear correlation to the concentration of the contrast medium (36).

One advantage of the CT technique is the ability to assess perfusion at the capillary level, which is more directly related to the metabolic requirements of the tissue than blood flow in the supplying vessel. Quantification of hepatic perfusion on dynamic CT, introduced by Miles et al (37) in 1991, has allowed separate evaluations of arterial and portal perfusion of the liver. To date, different methodologies, such as the maximum slope method $(2,34,35,37-41)$ and the dual-input one-compartmental model $(16,42,43)$ have been described. In the present study, we used the deconvolution method, which is a well-established compartmental modeling technique (17).

The main purpose of the present study was to assess the utility and clinical usefulness of CT perfusion for quantitative 
assessment of the severity of disease and fibrotic change in patients with chronic liver diseases. The value of each perfusion parameter of the liver parenchyma of patients free of liver disease was concordant with the normal values published in previous studies $(34,38)$. The hepatic perfusion parameters of TBF and HAF of patients with chronic liver diseases were significantly altered in accordance with the degree of cirrhosis. These hemodynamic changes can be explained by the structural alterations that occur in cirrhosis. The increased vascular resistance in the cirrhotic liver reduces portal perfusion $(1,2)$. The reduction of portal perfusion is buffered by liver arterialization, increasing the arterial fraction of liver perfusion $(1,3,4)$. However, the increased arterial perfusion is often not sufficient to maintain total liver perfusion in cirrhosis because of the high extrahepatic portosystemic shunting $(1,5)$, which explains the reduction of total liver perfusion noted in our study.

Several groups reported that portal perfusion in cirrhosis, measured by CT, decreases in proportion with the degree of hepatic dysfunction, determined by clinical [e.g., the ChildPugh classification system (16)] and biological [e.g., prothrombin ratio (2)] parameters. The present results of TBF tendency to decrease and HAF tendency to increase in parallel with the severity of chronic liver disease are in agreement with the results of the aforementioned previous studies $(2,16)$.

Hepatic fibrosis, a common response to chronic inflammatory conditions such as viral hepatitis, eventually leads to cirrhosis. Normally, collagen constitutes $4 \%$ of the liver protein. In cirrhosis, this proportion increases to $15-30 \%$ because of excessive deposition within the space of Disse and defenestration of the basal laminae, sinusoids and hepatic vein. This results in a considerable increase in vascular resistance, with subsequent increase in portal vein pressure from the normal 6-10 to $20-30 \mathrm{mmHg}$. Thus, portal perfusion decreases in patients with cirrhosis $(44,45)$. Despite its invasiveness, liver biopsy remains the gold standard for the diagnosis of cirrhosis (46). An interesting finding of our study was that the perfusion changes of TBF and HAF in patients with chronic liver disease significantly correlated with disease severity and fibrotic grade of the liver. These results suggest that the value of CT perfusion can be useful for long-term follow-up of patients with chronic liver disease. Determination of the prognosis of such patients should be further assessed (2).

Our study had certain limitations. First, the aorta and portal vein should always be included in the scan section for the calculation process. Second, a maximum of $20 \mathrm{~mm}$ width could be scanned on cine-mode, which thus limited the study to cover only the porta hepatic area. However, a wider detector with 32-40 mm width is available in the newest model. Third, even though we employed low-dose X-ray, high-dose radiation exposure cannot be avoided during the CT perfusion study. However, it is expected that new techniques, such as the quantum noise filter (47), can reduce the exposure dose.

In conclusion, CT perfusion is a non-invasive, safe technique for quantifying hepatic perfusion parameters. These parameters correlated significantly with the severity of chronic liver disease and the pathological degree of fibrosis. Our study indicated that quantitative measurement of hepatic tissue blood flow by perfusion CT is useful for the evaluation of the severity of chronic liver disease, fibrotic change and also for follow-up of patients with chronic hepatitis.

\section{References}

1. Leen E, Goldberg JA, Anderson JR, et al: Hepatic perfusion changes in patients with liver metastases: comparison with those patients with cirrhosis. Gut 34: 554-557, 1993.

2. Tsushima Y, Blomley MJ, Kusano S and Endo K: The portal component of hepatic perfusion measured by dynamic CT: an indicator of hepatic parenchymal damage. Dig Dis Sci 44: 1632-1638, 1999.

3. Lautt WW: Mechanism and role of intrinsic regulation of hepatic arterial blood flow: hepatic arterial buffer response. Am J Physiol 249: G549-G556, 1985.

4. Kleber G, Steudel N, Behrmann C, et al: Hepatic arterial flow volume and reserve in patients with cirrhosis: use of intra-arterial Doppler and adenosine infusion. Gastroenterology 116: 906-914, 1999.

5. Reichen J, Egger B, Ohara N, Zeltner TB, Zysset T and Zimmermann A: Determinants of hepatic function in liver cirrhosis in the rat: multivariate analysis. J Clin Invest 82: 2069-2076, 1988.

6. Keiding S: Drug administration to liver patients: aspects of liver pathophysiology. Semin Liver Dis 15: 268-282, 1995.

7. Molino G, Avagnina P, Belforte G and Bircher J: Assessment of the hepatic circulation in humans: new concepts based on evidence derived from a D-sorbitol clearance method. J Lab Clin Med 131: 393-405, 1998 .

8. Ohnishi K, Saito M, Nakayama T, et al: Portal venous hemodynamics in chronic liver disease: effects of posture change and exercise. Radiology 155: 757-761, 1985.

9. Walsh KM, Leen E, MacSween RN and Morris AJ: Hepatic blood flow changes in chronic hepatitis $\mathrm{C}$ measured by duplex Doppler color sonography: relationship to histological features. Dig Dis Sci 43: 2584-2590, 1998.

10. Leen E, Goldberg JA, Angerson WJ and McArdle CS: Potential role of doppler perfusion index in selection of patients with colorectal cancer for adjuvant chemotherapy. Lancet 355: 34-37, 2000.

11. Leen E, Goldberg JA, Robertson J, et al: Early detection of occult colorectal hepatic metastases using duplex colour Doppler sonography. Br J Surg 80: 1249-1251, 1993.

12. Blomley MJ, Lim AK, Harvey CJ, et al: Liver microbubble transit time compared with histology and Child-Pugh score in diffuse liver disease: a cross sectional study. Gut 52: 1188-1193, 2003.

13. Martin-Comin J, Mora J, Figueras J, et al: Calculation of portal contribution to hepatic blood flow with $99 \mathrm{mTc}$-microcolloids. A non-invasive method to diagnose liver graft rejection. J Nucl Med 29: 1776-1780, 1988.

14. Iwasa M, Nakamura K, Nakagawa T, et al: Single photon emission computed tomography to determine effective hepatic blood flow and intrahepatic shunting. Hepatology 21: 359-365, 1995.

15. Ziegler SI, Haberkorn U, Byrne H, et al: Measurement of liver blood flow using oxygen-15 labelled water and dynamic positron emission tomography: limitation of model description. Eur J Nucl Med 23: 169-177, 1996.

16. Van Beers BE, Leconte I, Materne R, Smith AM, Jamart J and Horsmans Y: Hepatic perfusion parameters in chronic liver disease: dynamic CT measurements correlated with disease severity. AJR Am J Roentgenol 176: 667-673, 2001.

17. Lee TY: Functional CT: physiological models. Trends Biotechnol 20: S3-S10, 2002.

18. Gressner AM: Liver fibrosis: perspectives in pathobiochemical research and clinical outlook. Eur J Clin Chem Clin Biochem 29: 293-311, 1997.

19. Naveau S, Poynard T, Benattar C, Bedossa P and Chaput JC: Alpha-2 macroglobulin and hepatic fibrosis: diagnostic interest. Dig Dis Sci 39: 2426-2432, 1994.

20. Yabu K, Kiyosawa K, Mori H, et al: Serum collagen type IV for the assessment of fibrosis and resistance to interferon therapy in chronic hepatitis C. Scand J Gastroenterol 29: 474-479, 1994.

21. Lopez-De Leon A and Rojkind M: A simple micromethod for collagen and total protein determination in formalin-fixed paraffinembedded sections. J Histochem Cytochem 33: 737-743, 1985.

22. Jimenez W, Pares A, Caballeria J, et al: Measurement of fibrosis in needle liver biopsies: evaluation of a colorimetric method. Hepatology 5: 815-818, 1985. 
23. Peters AM, Gunasekera RD, Henderson BL, et al: Non-invasive measurement of blood flow and extraction fraction. Nucl Med Commun 8: 823-837, 1987.

24. Peters AM, Brown J, Hartnell GG, Myers MJ, Haskell C and Lavender JP: Non-invasive measurement of renal blood flow with ${ }^{99 \mathrm{~m}}$ Tc DTPA: a comparison with radiolabeled microspheres. Cardiovasc Res 21: 830-834, 1987.

25. Gratz KF: Functional scintigraphy in the follow-up of transplants. Nuklearmedizin 32: 215-220, 1993.

26. Sarper R, Fajman WA, Rypins EB, et al: A non-invasive method for measuring portal venous/ total hepatic blood flow by hepatosplenic radionuclide angiography. Radiology 141: 179-184, 1981.

27. Fleming JS, Ackery DM, Walmsley BH ans Karran SJ. Scintigraphic estimate of arterial and portal blood supply to the liver. J Nucl Med 24: 1108-1113, 1983.

28. Parkin A, Robinson PJ, Baxter P, Leveson SH, Wiggins PA and Giles GR: Liver perfusion scintigraphy: method, normal range and laparotomy correlation in 100 patients. Nucl Med Commun 4: 395-402, 1983

29. O'Conor MK, MacMathuna P and Keeling PWN: Hepatic arterial and portal venous components of liver blood flow: a dynamic scintigraphic study. J Nucl Med 29: 466-472, 1988.

30. Defrancq J, Trotteur G and Dondelinger RF: Duplex ultrasonographic evaluation of liver transplants. Acta Radiol 34: 478-481, 1993.

31. Nolton A and Sproat IA: Hepatic artery thrombosis after liver transplantation: temporal accuracy of diagnosis with duplex US and the syndrome of impending thrombosis. Radiology 198: 553-559, 1996.

32. Sabba C, Ferraioli G, Sarin SK, Lerner E, Groszmann RJ and Taylor KJ: Feasibility spectrum for Doppler flowmetry of splanchnic vessels in normal and cirrhotic populations. J Ultrasound Med 9: 705-710, 1990.

33. Bosch J and Garcia-Pagan JC: Complications of cirrhosis. I. Portal hypertension. J Hepatol 32 (Suppl. 1): S141-S156, 2000.

34. Miles KA, Hayball MP and Dixon AK: Functional images of hepatic perfusion obtained with dynamic CT. Radiology 188 : 405-411, 1993.

35. Bader TR, Herneth AM, Blaicher W, et al: Hepatic perfusion after liver transplantation: non-invasive measurement with dynamic single-section CT. Radiology 209: 129-134, 1998.
36. Brasch RC, Weinmann HJ and Wesbey GE: Contrast-enhanced NMR imaging: animal studies using gadolinium-DTPA complex. AJR Am J Roentgenol 142: 625-630, 1984.

37. Miles KA: Measurement of tissue perfusion by dynamic computed tomography. Br J Radiol 64: 409-412, 1991.

38. Blomley MJ, Coulden R, Dawson P, et al: Liver perfusion studied with ultrafast CT. J Comput Assist Tomogr 19: 424-433, 1995.

39. Bader TR, Grabenwöger F, Prokesch RW and Krause W: Measurement of hepatic perfusion with dynamic computed tomography, assessment of normal values and comparison of two methods to compensate for motion artifacts. Invest Radiol 35: 539-547, 2000.

40. Leggett DA, Kelley BB, Bunce IH and Miles KA: Colorectal cancer: diagnostic potential of CT measurements of hepatic perfusion and implications for contrast enhancement protocols. Radiology 205: 716-720, 1997.

41. Miles KA, Leggett DA, Kelley BB, Hayball MP, Sinnatamby R and Bunce I: In vivo assessment of neovascularization of liver metastases using perfusion CT. Br J Radiol 71: 276-281, 1998.

42. Materne R, van Beers BE, Smith AM, et al: Non-invasive quantification of liver perfusion with dynamic computed tomography and a dual-input one-compartmental model. Clin Sci 99: 517-525, 2000.

43. Cuenod CA, Leconte I, Siauve N, et al: Early changes in liver perfusion caused by occult metastases in rats: detection with quantitative CT. Radiology 218: 556-561, 2001.

44. Orrego H, Blendis LM, Crossley IR, et al: Correlation of intrahepatic pressure with collagen in the Disse space and hepatomegaly in humans and in the rat. Gastroenterology 80: 546-556, 1981

45. Craig JR: Liver. In: Anderson's pathology. 9th edition. Kissane JM (ed). C.V. Mosby, Princeton, NJ, pp1199-1320, 1990.

46. Pagliaro L, Rinaldi F, Craxi A, et al: Percutaneous blind biopsy versus laparoscopy with guided biopsy in diagnosis of cirrhosis: a prospective, randomized trial. Dig Dis Sci 28: 39-43, 1983.

47. Okumura M, Toyoshima N, Katada K and Sasaki M: Performance evolution for image filters used for CT images. Radiological Society of North America, Scientific Assembly and Annual Meeting Program: 720, 2003. 